\title{
Guests' Desire for Relational Closeness with Hosts: The Roles of Attachment Styles
}

\author{
Srikanth Beldona* and Hemant V Kher ${ }^{\dagger}$
}

\begin{abstract}
Extant research is increasingly recognising the importance of customer attachment styles in service settings because of their significance in relationship marketing. This study examines the impact of guest attachment styles on the desire for relational closeness with hosts using perceived hospitality as a mediator of service evaluation. Findings show that guests with higher levels of attachment anxiety seek closer relationships with hosts and those with higher levels of attachment avoidance spurn efforts towards relational closeness. Also, perceived hospitality mediates only the impact of attachment avoidance on the desire for relational closeness. Theoretical and practical implications are discussed.
\end{abstract}

Keywords: Attachment styles, Perceived hospitality, Relationship marketing, Relational closeness

"Department of Hospitality Business Management, Alfred Lerner College of Business \& Economics, University of Delaware, Newark, Delaware, USA; beldona@udel.edu

† Department of Business Administration, Alfred Lerner College of Business \& Economics, University of Delaware, Newark, Delaware, USA; kher@udel.edu 


\section{GETTING TOO CLOSE? Guest Attachment Styles in Hospitality}

\section{Introduction}

Relationship marketing is of significant importance to the hospitality industry. In this context, hospitality firms are known to have relationships with guests that vary based on relationship length, intensity and the frequency of interactions. This in turn underlines the importance of studying guest behaviours at the individual level such that firms can employ appropriate strategies in enhancing relationships with them. One such behavioural element is an individual's attachment style (Bowlby 1969; Brennan, Clark, and Shaver 1988), which has recently attracted attention in the marketing domain (Thomson and Johnson 2006; Paulssen and Fournier 2007; Swaminathan, Stilley, and Ahluwalia 2009; Vlachos and Vrechopoulos 2012; Mende and Bolton 2011; Mende, Bolton and Bitner 2013).

Attachment styles are characterised by the propensity of individuals to seek or avoid relational attachment. While attachment avoidance is characterised by the suppression of feelings in interpersonal contexts, attachment anxiety involves the advancement of feelings and the pursuit of intimacy and closeness with partners. In service settings, attachment styles have been found to reflect a person's propensity to be receptive to relationship marketing efforts and have been determined to impact service evaluation and the desire for closeness with firms (Mende and Bolton 2011; Mende, Bolton and Bitner, 2013). While previous studies have examined their impacts in service settings where customer-provider relationships were longer in duration (typically years), little is known about how attachment styles play out in short-term relational settings (typically days) such as hospitality. Host-guest relationships in hospitality-based experiences also arguably have richer effective content.

The primary purpose of this study is to examine the impact of guest attachment styles on the desire for relational closeness with hosts. In doing so, this study uses a contextual performance measure of service evaluation for a hospitality setting namely, 
perceived hospitality and examines relationships between the attachment styles, perceived hospitality and the desire for relational closeness (DRC). The hypotheses are tested using Structural Equation Modeling (SEM). Theoretical and practical implications of the results are provided for researchers and managers.

\section{Conceptual Overview}

\subsection{Perceived Hospitality}

While customer satisfaction is a holistic measure of service evaluation in the extant literature (Oliver, 1997), the nature and characteristics inherent in hospitality are better captured using a more contextual measure of performance. Literature in theology, philosophy and hospitality management highlights generosity, caring and individual attention as important aspects of hospitality (King, 1995; Lashley, 2000; Scanlan and McPhail, 2000). The origin of the word "hospitality" stems from the Latin word "hospes", which also means "guest-master" or "master of guests", i.e. the host. The etymology of the word "guest" alludes to a stranger, indicating that the place of service is at the host's i.e., not their own. Definitions in two dictionaries highlight a common theme of generosity and caring as important dispensations of hospitality. The Oxford dictionary defines it as "the friendly and generous reception and entertainment of guests, visitors, or strangers" (Oxford 2012). The Webster dictionary contends that it is "providing for a pleasant and sustaining environment with generosity and cordiality" (Webster 2012).

Two elements in a hospitality-based experience differentiate it from other services (Beldona and Kher 2015). First is that the nature of the service is of a personal and accommodating nature that is based on the "concept of home". Secondly, the service should be interpersonally facilitated. The term personal here means services that are targeted at people and their psychobiological needs (Bowen 1990). The personal needs of an accommodating nature also imply that consumption takes place at the provider's premises (Hepple et al. 1990; King 1995; Lashley 2000). The personal needs satisfied are both instrumental and hedonic (Khan and Dhar 2004). 
Instrumental personal needs are those that drive consumers to maintain a psychobiological equilibrium when away from their homes such as food, shelter and so on. Hedonic personal needs are driven by consumers' desire to explore, engage and consume new experiences. This intertwined combination of instrumental and hedonic needs pave the way for mixed emotions in the evaluation of hospitality-based experiences.

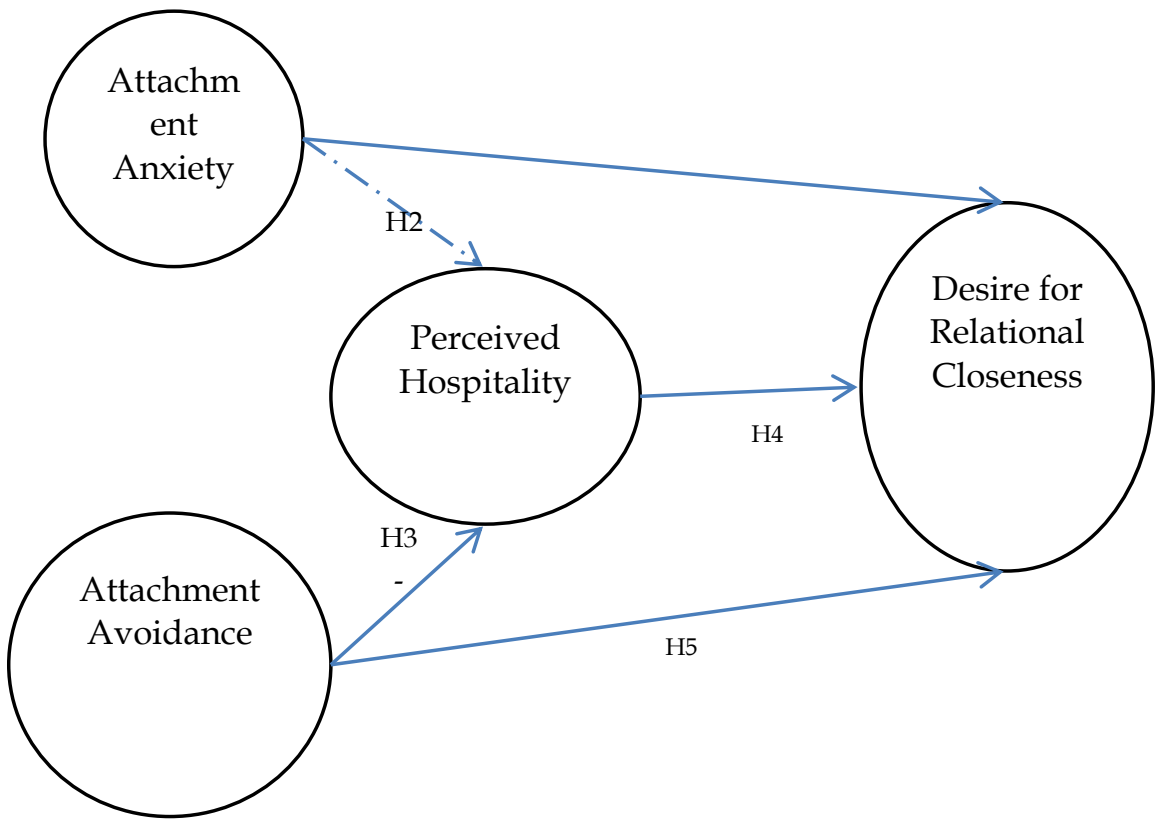

Figure 1: Conceptual Model

Since the host (provider) and guest (customer) are central for hospitality to prevail, the phenomenon is also fundamentally interpersonal. In this context, human representatives are often perceived to be the service itself (Shostack, 1977). Put differently, customers largely evaluate a service using the frontline staff and the quality of interpersonal interactions that they provided (Bitner, Booms and Tetreault, 1990; Parasuraman, Zeithaml and Berry, 1988). Therefore perceived hospitality depends on the host's ability to address this duality of needs: a) psychobiological needs that stem from customers' perceived discomfort from being separated from their homes, and b) also provided for entertainment that is relevant to customers' hedonic needs (Beldona and Kher, 2015). To 
accommodate is to make way to enable an activity or experience, which then means that a dispensation of generosity is important. Catering to guests' perceived discomfort from being separated from their homes highlights the importance of individualised attention. When viewed holistically, perceived hospitality is an attitudinal judgment of a host's dispensation of generosity combined with the level of individualised attention provided. Eventually, good hospitality alleviates negative aspects of the home such as boredom, fatigue and so on while also providing for functionality and entertainment that is relevant to their instrumental and hedonic needs.

\subsection{Desire for Relational Closeness}

Customer orientation also has an impact on relationship quality, which in turn has a strong effect on positive word-of-mouth (Macintosh 2007). Relationship marketing theory for the most part outlines that customer relationship with firms vary on a continuum from transactional to highly relational bonds (Garbarino and Johnson 1999). Mende and Bolton (2011) define the desire for relational closeness as a customer's systematic preference for frequent, diverse and mutually beneficial customer relationship management(CRM) related interactions with a firm. It is based on the premise that the customer-firm relationship is a dyadic phenomenon, and that it requires a prevailing sense of mutuality between the two parties (Weitz 1981). Customers have to demonstrate a propensity for relational closeness for the relationship to actualise (Christy, Oliver, and Penn 1996; Schutz 1992).

\subsection{Perceived Hospitality and the Desire for Relational Closeness}

Findings show that for people with low- relational (transactional) orientation, customer satisfaction mediates the relationship between attitudes and future intentions as opposed to commitment and trust (which are affective constructs) that mediate the same relationship for high relational customers. This sense of mutuality also prevails in hospitality-based experiences, which are relatively rich in interpersonal interactions. This is because mutuality is driven by interdependence between the host and guest, which can set the stage for relational closeness with firms (Kelley et al. 1983). 
Since interdependence implies frequent interactions that are mutually beneficial, customers have to first perceive strong levels of hospitality delivered by the firm if they are expected to desire relational closeness with it. Therefore, it is posited that

H1: Perceived hospitality will be positively related to the desire for relational closeness with firms in HBE settings.

\subsection{Guest Attachment Styles}

The approach-avoidance framework in social psychology literature distinguishes individual motivations towards the achievement of goals (Elliott 1999). In the approach perspective, the focus is towards the attainment of goals through engagement in positive experiences and activities. In contrast, the avoidance perspective focuses on goal attainment through the avoidance of conflict and negative outcomes. The approach-avoidance framework was integrated into attachment theory, which conceptually outlines the tenets of human connectedness with people, objects and contexts. Two distinctive attachment styles, attachment anxiety and attachment avoidance differentiate human approaches to interconnectedness in relational settings underpinned by the approach-avoidance framework. Individuals who advance their feelings of attachment by seeking intimacy and closeness with partners are believed to be high on attachment anxiety. On the other hand, those who suppress their attachment orientation to limit potentially adverse situations and conflicts are considered to be high on attachment avoidance.

This dichotomy of attachment orientation has been applied in the marketing context to explain customer behaviour in consumption situations. Customer attachment anxiety is defined as the extent to which a consumer worries that a firm/service employee is unavailable at times of need, seeks approval and fears rejection and abandonment from the firm/service employee (Mende and Bolton 2011). In contrast, customer attachment avoidance is a reflection of mistrust towards a firm/service employee and is characterised by self-reliance and fears of dependence and emotional cognitive distance (Mende and Bolton 2011). 


\subsection{Attachment Theory, Perceived Hospitality and Desire for Relational Closeness}

A relationship requires a prevailing sense of mutuality between the marketer and the customer (Palmatier et al. 2006). However, not all customers have the same relational orientation towards a firm or a service employee (Barnes 1997; Bendapudi and Berry 1997). Customer relationships with firms vary on a continuum from transactional to highly relational bonds (Garbarino and Johnson 1999; Pillai and Sharma 2003). Also, the impact of the relational orientation of customers towards a firm has a significant impact on repurchase and word of mouth behaviours (Garbarino and Johnson 1999). In hospitality too, the host-guest dynamic is a dyadic phenomenon strongly underpinned by reciprocity. As much as the host should facilitate service delivery pleasantly and courteously, the guest has to oblige and perform his/her role appropriately as well. In other words, the guest has to reciprocate to a host's relational overtures to augment interpersonal engagement that is so integral to hospitality.

Viewed from the attachment anxiety/attachment avoidance perspective, Guiry (1992) identified two distinct approaches to service engagement namely, customer dependence and customer autonomy. With dependence, customers seek guidance and assistance during consumption but in the case of autonomy, they desire independence to make decisions on their own. Importantly, dependent customers seek greater reproach from interpersonal service typical in HBEs as opposed to autonomous customers.

The host-guest relationship is contingent upon the extent to which a guest feels dependent on the host. When viewed from the attachment anxiety/attachment avoidance perspective, guest attachment anxiety is characterised by dependence/care-seeking and attachment avoidance by independence or greater distance from the firm/employee. Add to this, higher levels of attachment anxiety or attachment avoidance result in high levels of dissatisfaction with the service provider (Mende and Bolton, 2011). Therefore,

H2: Attachment anxiety will be negatively related to perceived hospitality. 
H3: Attachment avoidance will be negatively related to perceived hospitality.

Since individuals who advance their feelings of attachment by seeking intimacy and closeness with partners are believed to be high on attachment anxiety, while those who suppress their attachment orientation to limit potentially adverse situations and conflicts are considered to be high on attachment avoidance. Therefore, it is posited that

H4: Attachment anxiety will be positively related to the desire for relational closeness.

H5: Attachment avoidance will be negatively related to the desire for relational closeness.

\section{Data and Measures}

\subsection{Data}

Data was collected using an online survey of US consumers using the services of a leading data provider. Respondents were asked to recall their most recent vacation trip wherein they stayed at a "hotel" or a "bed and breakfast"(B\&B). Hotels and B\&Bs are the most widely used hosted commercial accommodations that travellers use. From a total of 2000 consumers polled, 307 responses were received indicating a $15 \%$ response rate. Given the relatively low response rate, the data was checked for non-response bias by comparing respondents based on when they responded to the survey i.e., (1) early, (2) between early and late, and (3) late across the key measures of perceived hospitality and the desire for relational closeness. ANOVA results indicated no statistically significant differences across the three categories.

Table 1: Descriptive Statistics

\begin{tabular}{lcll}
\hline Gender & $\%^{*}$ & Education & $\%$ \\
\hline Female & 63.3 & High School or Less & 23.0 \\
\hline Male & 36.7 & $\begin{array}{l}\text { Some College No } \\
\text { Degree }\end{array}$ & 32.2 \\
\hline
\end{tabular}




\begin{tabular}{|c|c|c|c|}
\hline $\begin{array}{l}\text { Type of } \\
\text { Accommodations }\end{array}$ & $\%$ & $\begin{array}{l}\text { Vocational Qual/No } \\
\text { Degree }\end{array}$ & 8.9 \\
\hline Budget & 18.7 & Associate Degree & 14.1 \\
\hline Mid-Scale & 48.1 & Bachelor Degree & 15.9 \\
\hline Upscale & 23.5 & Post Graduate Degree & 5.9 \\
\hline Bed \& Breakfast & 9.7 & & \\
\hline Age & $\%$ & Employment Status & $\%$ \\
\hline $18-25$ & 8.5 & Student & 5.5 \\
\hline $26-33$ & 13.7 & Homemaker & 11.1 \\
\hline $34-41$ & 19.6 & Not Employed & 9.6 \\
\hline $42-49$ & 28.5 & Self-Employed & 12.9 \\
\hline $50-57$ & 20.7 & Employed & 43.2 \\
\hline$>=58$ & 8.9 & Retired & 17.7 \\
\hline Household Income & $\%$ & When Trip Happened & $\%$ \\
\hline$<\$ 25,000$ & 23.6 & $\begin{array}{l}\text { Less than a Month } \\
\text { Ago }\end{array}$ & 16.4 \\
\hline$\$ 25,001-\$ 50,000$ & 37.5 & 2-3 Months Ago & 18.6 \\
\hline$-\$ 50,001-\$ 75,000$ & 22.9 & 4-6 Months Ago & 20.8 \\
\hline$\$ 75,001-\$ 100,000$ & 11.1 & $\begin{array}{l}\text { More than } 6 \text { Months } \\
\text { Ago }\end{array}$ & 44.2 \\
\hline$\$ 100,001-\$ 125,000$ & 2.4 & & \\
\hline$>\$ 125,000$ & 2.4 & & \\
\hline
\end{tabular}

The sample's key demographic characteristics were also examined with leisure customers in an American Hotel and Lodging Association study (AHLA, 2011) and the representativeness was found to be comparable. Specifically, the AHLA's study had $74 \%$ of leisure customers that were 35 years or older compared to this study which had $78 \%$ at the same age bracket. Also, in the AHLA's study, a majority ofcustomers typically paid $\$ 105$ per room per 
night. In this study, the majority $(67 \%)$ stayed in mid-scale or budget hotels where the aggregate rate is comparable to the one in the AHLA study.

\subsection{Measures}

Items for perceived hospitality were developed using a synthesis of the literature. Six items were first tested in two pilot surveys with an administrative staff built on the concept of generosity in hospitality (King, 1995) and individualised attention. While one item was discarded from the original six-item scale to ensure content validity based on expert feedback, another did not load as per the requirements. Attachment styles were adapted from Mende and Bolton (2011) to fit an HBE context. The desire for relational closeness scales was an abridged version of Mende et al. (2011).

Table 2: Construct Measuresand EFA Results

\begin{tabular}{lll}
\hline Construct & Loading & $\begin{array}{c}\text { Eigen } \\
\text { Value }\end{array}$ \\
& Variance
\end{tabular}

Perceived Hospitality ( $a=0.80, C R$

$=0.83)$ )

I was touched by the care and 0.830

attention shown by hotel/B\&B staff.

I am glad that the services in this 0.859

hotel/B\&B met my travel needs

adequately.

I felt like just another number when 0.589

it came to the nature of service in

this hotel/B\&B. (R)

I was impressed by the extent to 0.842

which staff at this Hotel/B\&B

sought to make customers

comfortable.

Desire for Relational Closeness ( $a=0$.

$87, C R=0.90$ ) 
This hotel/B\&B should contact me once in 3 months just to stay in touch.

I would like to have a closer relationship with this hotel/B\&B.

0.881

Customer Attachment Anxiety ( $a=0$.

92, $C R=0.92$ )

In hotels, I worry about being 0.84 neglected as a customer.

Hotel staff tends to change how 0.89 they treat people for no reason.

I worry that hotel staff don't like 0.92 their customers.

I worry that hotel employees don't 0.93 care much about their customers.

Customer Attachment Avoidance ( $a=0$. $85, C R=0.85$ )

It is a comfortable feeling to depend on hotel staff. (R)

0.84

I am comfortable having a close relationship with a hotel employee. (R)

0.80

It is easy for me to feel warm and friendly with hotel employees. (R) $\quad 0.84$

It helps to turn to hotel staff at times of need/help (R)

Principal components analysis was used to establish construct and discriminant validity, the results of which are presented in Table 2. Reliability and composite reliability of the scales are provided in Table 2 and were all above the prescribed cut off of 0.70 (Nunnally, 1979). Discriminant validity was also established using the average variance extracted (AVE) method (Fornell and Larcker, 1981). 
Table 3: Discriminant Validity Results (Fornell \& Larcker Test, 1981)

(AVE Values on the Diagonal and Squared Correlations in remaining cells)

\begin{tabular}{lllll}
\hline & PH & ANX & AVD & DRC \\
\hline PH & $\mathbf{0 . 5 6 7}$ & & & \\
\hline ANX & 0.002 & $\mathbf{0 . 7 2 3}$ & & \\
\hline AVD & 0.312 & 0.038 & $\mathbf{0 . 5 7 8}$ & \\
\hline SAC & 0.099 & 0.133 & 0.163 & $\mathbf{0 . 7 8 0}$ \\
\hline
\end{tabular}

Table 3 shows the results of the discriminant validity test where the AVE values ranged from 0.59 to 0.78 and thereby exceeded the recommended cutoff value of 0.50 . These were also greater than the squared correlations as suggested by Fornell and Larcker (1981). Convergent validity of constructs was also confirmed using Confirmatory Factor Analysis (CFA). All item loadings for each of the factors in the measurement model were significant at the .01 level (Hair, Black, Anderson and Tatham, 2006).

\section{Findings}

Analysis was conducted in two stages. The first stage involved a descriptive exploration using Analysis of Variance (ANOVA) to determine differences in perceived hospitality and the desire for relational closeness based on the type of lodging establishment patronised. Here, the combined means of the items in the constructs of interest (Perceived Hospitality and the Desire for Relational Closeness), served as the dependent variables for each ANOVA model. The independent variable for each model was the type of lodging accommodation, which was coded as 1=Budget/Economy, 2=Midscale, $3=$ Upscale and $4=\mathrm{B} \& \mathrm{~B}$. Table 4 shows the results of the ANOVA analysis. Both models were statistically significant at $\mathrm{p}<.05$ indicating that perceived hospitality and the desire for relational closeness varied based on the type of hospitality setting. 


\section{Figure 2: Model Results}

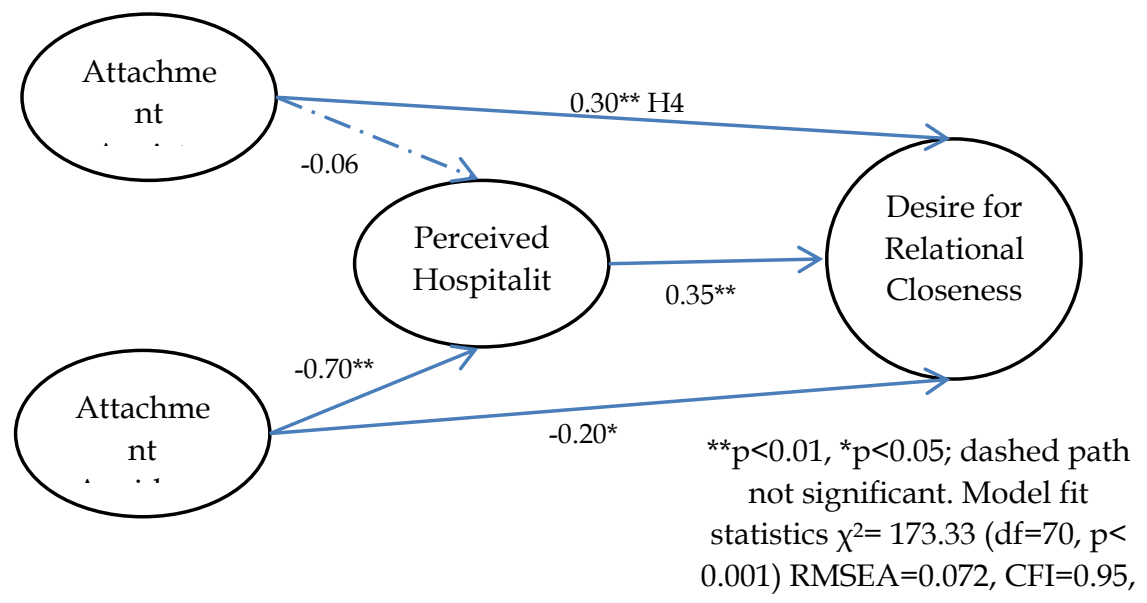

Table 4 also shows the post hoc comparisons across the four groups for the two constructs. Notably, perceived hospitality was greater in upscale hotels as opposed to midscale and budget hotels. Additionally, B\&Bs reported the highest perceptions of hospitality, and this was significantly greater when compared with midscale and upscale hotels. However, when it came to the desire for relational closeness, B\&Bs reported significantly higher levels compared to all mainstream hotels but there were no differences between mainstream hotels. Both models were ascertained only after all assumptions of ANOVA were met.

Table 4: Differences in PH and DRC by Accommodation Type Post Hoc Tests(N=307)

Significant

Difference

BU MI UP BB $\mathrm{s}$

\begin{tabular}{|c|c|c|c|c|c|}
\hline $\begin{array}{l}\text { Perceived Hospitality } \\
\left(\begin{array}{l}(\mathrm{F}=5.18, \\
\mathrm{df}=3,304, \mathrm{p}<.002)\end{array}\right.\end{array}$ & 4.33 & 4.68 & 4.99 & 5.29 & $\begin{array}{l}U P>B U^{*} \\
B B>B U^{* *} \\
B B>M I^{*}\end{array}$ \\
\hline $\begin{array}{l}\text { Desire for Relational } \\
\text { Closeness } \\
(\mathrm{F}=4.02 \text {, }\end{array}$ & 3.49 & 3.44 & 3.44 & 4.54 & $\begin{array}{l}B B>B U^{*} \\
B B>M I^{*}\end{array}$ \\
\hline
\end{tabular}


$B U=B u d g e t / E c o n o m y, M I=$ Midscale $, U P=U p s c a l e / L u x u r y, B B=B e d \quad \mathcal{E}$ Breakfast,

Scale $=1$ - =Strongly Disagree $\& 7=$ Strongly Agree ${ }^{*} p<.05,{ }^{* *} p<.01,{ }^{* * *} p<.001$

The second stage sought to validate the proposed model and hypotheses using structural equation modelling with MPlus 7.11. Figure 2 displays the SEM results $(x 2=173.33,(d f=70, p<0.001)$ RMSEA=0.072, $\quad$ CFI=0.95, $\quad$ TLI=0.94, SRMR=0.078) with standardised path coefficients showing all paths. H1 posited a positive relationship between perceived hospitality and the desire for relational closeness and was supported $(\beta=0.35, p<0.001)$. Specific to an HBE setting, this finding validates the notion that to enhance repeat patronage, guests must perceive high levels of hospitality.

The relationship between attachment anxiety and perceived hospitality was non-significant $(\beta=-0.06)$, indicating a lack of support for H2. However, attachment avoidance $\left(\beta=-0.70^{* *}\right)$ had a significant negative relationship with perceived hospitality thereby providing support for $\mathrm{H} 3$. Nonetheless, this mix of findings in $\mathrm{H} 2$ and $\mathrm{H} 3$ substantiate that the effect of attachment anxiety on perceived hospitality is significantly lesser when compared with attachment avoidance. In other words, anxiety characterised by dependence and a greater reproach towards interpersonal service will be relatively more receptive and appreciative to hospitality overtures compared to avoidance characterised by autonomy and independence.

Lastly, the positive and significant path from attachment anxiety to the desire for relational closeness $\left(\beta=0.30^{* *}\right)$ and the negative and significant path from attachment avoidance to the desire for relational closeness $\left(\beta=-0.20^{* *}\right)$ provide support for $\mathrm{H} 4$ and $\mathrm{H} 5$. The proclivity to seek out interpersonal interactions as characterized by attachment anxiety among guests makes them more receptive to forging social bonds with hosts. Conversely, 
guests who are independently inclined as characterised by attachment avoidance spurn relationships with hosts.

\section{Discussion \& Conclusions}

At the outset, this study shows that perceptions of hospitality and the desire for relational closeness vary based on the type of hospitality establishment being patronised. Findings indicate that guests perceive hospitality to be the highest in B\&Bs and upscale hotels, followed by midscale and budget hotels. In the case of upscale hotels, this can be explained by the arguably finer amenities and the relatively higher personalised attention levels they provide over midscale and budget hotels. B\&Bs on the other hand, provide unique/distinctive hospitality experiences with rich levels of interpersonal attention to guest needs. Their intimate and smaller-scale settings add to their prowess in generating higher perceptions of hospitality, when compared with midscale and economy hotels.

However, when it came to the desire for relational closeness, there were stark differences between $B \& B s$ on one hand and three mainstream hotels on the other. B\&Bs provide rich interpersonal interactions and generate greater social capital with guests (Tang, 2015), and this clearly showed why guests' desire for relational closeness was greater when compared with all mainstream hotels. Within mainstream hotels, there were no differences when it came to the desire for relational closeness.

\subsection{Theoretical Implications and Future Research}

The results of the empirical model add to the body of knowledge in hospitality literature about customer attachment styles. The study supported most of the hypotheses except $\mathrm{H} 2$ that posited a significant negative relationship between attachment anxiety and perceived hospitality. Regardless, these findings can be interpreted as saying that stronger avoidant attachment styles will likely report lower perceptions of hospitality than anxiety-dominated attachment styles.

The key theoretical implication here relates to the integration of attachment styles into the broader hospitality literature as it relates 
to the desire for closeness and relationship building. Secondly, the study paves the way for greater examination of hospitality provision and the host-guest relationship because of the emergence of personally hosted commercial accommodations such as Airbnb and HomeAway. Arguably, the mainstream hotel industry will have to recalibrate its service strategies to a more personalised level so as challenge the intimacy and authenticity of personally-hosted commercial accommodations. Personally hosted accommodations do not pursue standardised service procedures commonly found in mainstream hotels, and arguably draw can draw greater evaluations of hospitality. At a theoretical level, this study's findings provide the foundational behavioural cues about customers and their evaluations of hospitality in both standardised (mainstream hotels) and non-standardised (B\&Bs) settings. Two key areas for future investigation are outlined below:

5.1.1. This study focussed only on guest attachment styles and their relationships with perceived hospitality and the desire for relational closeness and found significant relationships. However, the authors contend that "host" attachment styles will arguably play a greater role in effective hospitality provision. A key hypothesis to be established empirically is if anxiety-dominant hosts(frontline staff) will be more attuned to guest needs given their proclivity towards interdependence as opposed to avoidantdominant hosts. Findings here can improve the selection and training of hostsat hospitality firms.

5.1.2. Applying the knowledge gleaned from guest attachment styles can help in better operationalisation of CRM initiatives especially in developing targeted communications. For example, do avoidant-dominant guests prefer financial rewards over emotional connectors such as birthdays and anniversaries? How should hosts communicate with guests before their stay using attachment styles as a guiding principle? What type of pre-stay information is more amenable to anxious-dominant guests as opposed to avoidantdominant guests? Future research can examine some key mechanisms in customer relationship management using attachment styles to improve our understanding of effective hospitality provision. 


\subsection{Practical Implications}

At a broad level, the findings address some key issues that have implications for the practice of relationship marketing in the hospitality industry. These can be distilled along with three main points namely service encounter management, (1) the service encounter, (2) relationship management as it relates to guest history profiles/preferences, relationship maintenance etc., and lastly (3) social media monitoring and management.

5.2.1.The first implication of the study's findings relates to how hospitality firms need to educate and train employees on the concept of guest attachment styles. This is because it helps anticipate and respond to guest needs better, which in turn can enrich the quality of interactionsin service encounters. Understanding the distinction between attachment styles can improve the uniqueness of hospitality provision in a balanced or nuanced way. Care should be taken to prevent seemingly avoidant guests from being aggressively courted with relational overtures. On the other hand, anxious guests should be engaged in a manner where reasonable concerns are placated while also conveying the features of the service offering with relevant detail.

Put differently, attachment styles should be used as a conceptual foundation to predicate guest behaviours and subsequently finetune service delivery and relational efforts. This is especially important in hospitality settings since they are typically rich in interpersonal interactions. Firms also need to examine the attachment orientation of frontline employees in the hiring process. Although this has to be established empirically, anxiety-dominant employees will likely be more attuned to guest needs given their proclivity towards interdependence as opposed to avoidantdominant employees that favour independence/autonomy.

5.2.2. A large part of relationship management comprises communicating with guests before, during, and after the stay. Firms can formulate customised communication strategies for guests based on their attachment styles. To achieve this effectively, hospitality firms need to effectively connect knowledge captured at the encounter level and other guest touchpoints to accordingly craft programs and procedures. Knowing whom to court for a closer 
relationship and the extent to which they prefer interactions can be very beneficial. Integrating knowledge about guest attachment styles into CRM systems can improve the efficacy of "if, when, and how" of relationship engagement. For example, attachment anxiety dominant customers can be more courted using personal agenda items such as birthdays and anniversaries along with financial perks as opposed to avoidant customers who may prefer financial perks only. The ability of CRM systems to store information about guest attachment styles, and subsequently target customers accordingly can significantly enhance the effectiveness of relationship marketing efforts in the hospitality industry.

5.2.3. A significant aspect of customer engagement is now conducted on social media platforms through the practice popularly known as reputation management. This involves monitoring and responding to customers on social networks and reviewing websites. Applying the tenets of attachment styles to understand how customers reflect on their experiences can be valuable for hospitality firms. Firms can deploy the right strategies to distinguish and connect with customers more effectively. Importantly, engaging with them by modifying the frequency of engagement based on preferences can also be of significant value.

\section{Limitations \& Conclusion}

This study focused only on leisure as the purpose of travel. Also, the study did not control for first-time and repeat visitation, which can arguably improve the explanatory level of the findings. Future research can model and conduct multi-group testing procedures using these variables to improve our understanding of attachment styles in hospitality settings.

In conclusion, the study ascertains that attachment styles do play a role in guests' desire for relational closeness with hospitality providers. A proclivity of greater attachment anxiety indicates a stronger desire to seek closeness with hospitality providers as opposed to attachment avoidance, which has the inverse effect. Findings also show that the perceptions of hospitality are greater with upscale hotels and B\&Bs. In the case of the "desire for relational closeness", customers showed significantly greater 
intentions towards B\&B's as opposed to mainstream hotels in general.

\section{References}

American Hotel \& Lodging Association. 2011. Lodging industry customer

profile.http:/ / www.ahla.com/content.aspx?id=32567 (accessed October 30, 2014).

Barnes, J. G. (1997), “Closeness, strength, and satisfaction: Examining the nature of relationships between providers of financial services and their retail customers", Psychology and Marketing, Vol. 14 No 8, pp. 765-790.

Beldona, S. and Kher, H. (2015), "The impact of customer sacrifice and attachment styles on perceived hospitality", Cornell Hospitality Quarterly, Vol. 56 No. 4, pp. 355-368.

Bendapudi, N. and Berry, L. (1997), "Customers' motivations for maintaining relationships with service providers", Journal of Retailing, Vol. 73 No. 1, pp. 15-37.

Bitner, M. J. Booms, B. H. and Tetreault, S. M. (1990), “The service encounter: Diagnosing unfavorable incidents", Journal of Marketing, Vol. 54, No. 1, pp. 71-84.

Bowen, J. (1990), "Development of a taxonomy of services to gain strategic marketing insights," Journal of the Academy of Marketing Science, Vol. 18, No. 1, pp. 43-48.

Bowlby, J. (1969), Attachment and Loss, Vol. 1: Attachment. New York: Basic Books.

Brennan, K. A. Clark, C.L. and Shaver, P.R. (1998), "Self-report measurement of adult attachment: An integrative overview," in J. A. Simpson and W. S. Rholes, Eds. Attachment Theory and Close Relationships, New York: Guilford, pp 46-76.

Christy, R. Oliver, G. and Penn, J. (1996), "Relationship marketing in consumer markets", Journal of Marketing Management, Vol. 12, No. 1-3, pp. 175-87. 
Elliott, A. J. (1999), "Approach and avoidance motivation and achievement goals", Educational Psychologist, Vol. 34 No. 3, pp. 169-189.

Garbarino, E. and Johnson, M.S. (1999). The different roles of satisfaction, trust, and commitment in customer relationships. Journal of Marketing, 63(2), 70-87.

Guiry, M. (1992). Consumer and employee roles in service encounters. In John F. Sherry, Jr. and Brian Sternthal, Vol 19, (Eds), Advances in Consumer Research, Association for Consumer Research, pp. 666-672.

Hair, J., Black, B. Babin, B., Anderson, R. and Tatham, R. (2006). MultivariateDataAnalysis( $6^{\text {th }}$ edition). $\quad$ UpperSaddleRiver, NJ:Prentice-Hall.

Hepple, J. Kipps, M. and Thomson, J. (1990), “The concept of hospitality and an evaluation of its applicability to the experience of hospital patients", International Journal of Hospitality Management, Vol. 9 No. 4, pp. 305-17.

Kelley, H. H. Berscheid, E. Christensen, A. Harvey, J. H. Huston, T. L. Levinger, G. McClintock, E. Peplau, L. A. and Peterson, D. R. (1983), "Analyzingcloserelationships", in H. H. Kelley, E. Berscheid, A. Christensen, J. H. Harvey, T. L. Huston, G. Levinger, E. McClintock, L. A. Peplauand D. R. Peterson(Eds.), Closerelationships. New York: Freeman, pp.20-67.

Khan, Usma and Ravi Dhar, R (2004), “A Behavioral Decision Theoretic Perspective on Hedonic and Utilitarian Choice", in Inside Consumption: Frontiers of Research on Consumer Motives Goals, and Desires, S. Ratneswhar and D. G. Mick, eds. London: Routledge, pp. 144-165.

King, C. A. (1995), "What is hospitality?" International Journal of Hospitality Management, Vol. 14, No. 3/4, pp. 219-234.

Lashley, C. (2000), "Towards a theoretical understanding", in C. Lashley and A. Morrison (Eds), In Search of Hospitality: Theoretical Perspectives and Debates. Butterworth-Heinemann, Oxford, pp. 281-304. 
Macintosh, G. (2007), "Customer orientation, relationship quality, and relational benefits to the firm", Journal of Services Marketing, Vol. 21, No 3, pp. 150-159.

Mende, M. Bolton, and R.N. (2011), “Why attachment security matters: How customers' attachment styles influence their relationships with service firms and service employees," Journal of Service Research, Vol. 14, No. 3, 285-301.

Mende, M. Bolton, R. N. and Bitner, M. J. (2013), “Decoding customer-firm relationships: How attachment styles help explain customers' preferences for closeness, repurchase intentions, and changes in relationship breadth", Journal of Marketing Research, Vol. 50, No. 1, pp. 125-142.

Oliver, R. L. (1997), Satisfaction: A Behavioral Perspective on the Consumer, New York, NY: Irwin McGraw-Hill.

Palmatier, R. W. Dant, R. Grewal, D. and Evans, K. R. (2006), "Factors influencing the effectiveness of relationship marketing: A meta-analysis", Journal of Marketing, Vol. 70, No. 4, pp. 136-153.

Parasuraman, A. Zeithmal, V. A. and Berry, L. (1988), "SERVQUAL: A multiple-item scale for measuring consumer perceptions of service quality", Journal of Retailing, Vol. 64, No. 1, pp. 12-40.

Paulssen, M. Fournier, S. (2007). Attachment security and the strength of commercial relationships: A longitudinal study. Discussion Paper No. 50, Department of Business and Economics, Humboldt University Berlin.

Pillai, K. G. and Sharma, A. (2003), “Mature relationships: Why does relational orientation turn into transactional orientation?" Industrial Marketing Management, Vol. 32 No. 8, pp. 643-651.

Scanlan, L. and Mc Phail, J. (2000), "Forming service relationships with hotel business travelers: The critical attributes to improve retention, Journal of Hospitality and Tourism Research, Vol. 24,No. 4, pp. 491-513. 
Schutz, W. (1992). "Beyond FIRO-B-Three new theory-derived measures-Elements B: Behavior, Elements F: Feelings, Elements S: Self", Psychological Reports, Vol. 70, pp. 915-37.

Shostack, G. L. (1977), "Breaking free from product marketing", Journal of Marketing, Vol. 41, No. 2, pp. 73-80.

Swaminathan V. Stilley, K. and Ahluwalia. R, (2009), "When brand personality matters: The moderating role of attachment styles", Journal of Consumer Research, Vol. 35, No. 6, pp. 9851002.

Tang, Ta-Wei. (2015), "Competing through customer social capital: The proactive personality of bed and breakfast operators", Asia Pacific Journal of Tourism Research, Vol. 20, No. 2, pp 133-151.

Thomson, M. and Johnson, A.R. (2006), "Marketplace and personal space: Investigating the differential effects of attachment style across relationship contexts", Psychology and Marketing, Vol. 23, No. 8, pp. 711-726.

Vlachos, P. A. and Vrechopoulos, A. (2012), "Consumer-retailer love and attachment: Antecedents and personality moderators", Journal of Retailing and Consumer Services, Vol. 19, No. 2, pp. 218-228.

Weitz, B. (1981), "Effectiveness in sales interactions: A contingency framework", Journal of Marketing, Vol. 45, No. 1, pp. 85-103. 